\title{
Photocatalytic air purifiers for indoor air: European standard and pilot room experiments
}

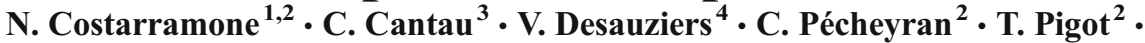

S. Lacombe ${ }^{2}$

\begin{abstract}
At the European level (CEN/TC386), some efforts are currently devoted to new standards for comparing the efficiency of commercial photocatalytic material/devices in various application fields. Concerning prototype or commercial indoor photocatalytic air purifiers designed for volatile organic compounds (VOC) abatement, the methodology is based on a laboratory airtight chamber. The photocatalytic function is demonstrated by the mineralization of a mixture of five VOCs. Experimental data were obtained for four selected commercial devices and three commercial materials: drop of VOC concentration, but also identification of secondary species (with special attention to formaldehyde), mineralization rates, and Clean Air Delivery Rate (CADR). With two efficient air purifiers, these laboratory experiments were compared to the results in two experimental rooms $\left(35-40 \mathrm{~m}^{3}\right)$ where air pollution was introduced through wooden floor and furniture. The systems' ageing was also studied. The safety of the commercial products was also assessed by the determination of nanoparticle release. Standardized tests are useful to rank photocatalytic air purifiers and passive materials and to discard inefficient ones. A good correlation between the standard experiments and the experimental room experiments was
\end{abstract}

S. Lacombe

sylvie.lacombe@univ-pau.fr

1 UT2A, Hélioparc, 2 Avenue du Président Angot, BP 1153, 64013 Pau cedex, France

2 IPREM, UMR CNRS 5254, Université de Pau et Pays de l'Adour Hélioparc, 2 Av. Pdt Angot, BP 1153, 64013 Pau cedex, France

3 NOBATEK, 67 rue de Mirambeau, 64600 Anglet, France

4 C2MA Ecole des Mines d'Alès, Hélioparc, 2 Av. Pdt Angot, BP 1153, 64013 Pau cedex, France found, even if in the latter case, the concentration of lower weight VOCs drops less quickly than that of heavier VOCs.

Keywords Airtight chamber - Clean Air Delivery Rate (CADR) · Mineralization · Formaldehyde · Terpenes · VOC . Photocatalysis

\section{Introduction}

Since a few years, the improvement of indoor air quality (IAQ) is a major concern of industrial countries. Indoor air pollutants are mainly volatile organic compounds (VOC), which impact human health (sick building syndrome or SBS), comfort and productivity (Jones 1999; Squinazi 2002; Bernstein et al. 2008; Leung 2015). Among several solutions to improve air quality, the use of air-purifying devices/ materials based on various technologies is promising (Zhang et al. 2011; Luengas et al. 2015). Advanced oxidation processes (AOP) such as cold plasma oxidation and/or photocatalysis are interesting solutions for indoor air treatment. Several photocatalytic air purifiers (PCO) devices were actually developed based on the activation of a photocatalytic media (incorporating $\mathrm{TiO}_{2}$ ) by UV light and including a fan to promote the contact with polluted air. Moreover, photocatalytic materials such as paints, varnishes, textiles, papers, ceramics, concrete, cement... combining depollution and self-cleaning properties are considered as passive PCO systems using natural or artificial light.

However, even if the suppliers certify a depolluting function, are these devices/materials efficient and safe under real indoor air conditions? How can their performances and harmlessness be determined?

Photocatalytic performances for air purification with various media and reactors have been investigated in 
many scientific works these last years (Zeltner and Tomkins 2005; Tomkins et al. 2005; Mo et al. 2009; Gunschera et al. 2016; Destaillats et al. 2012). Many VOCs could be mineralized by this technique, well suitable for the low indoor air concentrations. Kolarik et al. (2010) have examined the effect of a photocatalytic air purifier on perceived air quality in rooms polluted by typical sources of indoor VOCs. They conclude that this purifier can supplement ventilation when indoor air is polluted mainly by building-related sources in case of unoccupied buildings but should be avoided when humans are present.

According to (Paz 2010), the main challenges for PCO air treatment are linked to:

- Pollutant mass transfer to the surface of the photocatalyst

- Pollutant adsorption on the photocatalytic media

- Contact time between polluted air and irradiated media

- Pollutant mineralization with limitation of by-product formation

- Deactivation of the photocatalytic media with time

- Optimization of the use of photons

- Adhesion of the photocatalyst to the substrate

The potential market development depends on the efficiency but also on the safety of the commercial materials and devices in terms of by-product emission and release of titanium dioxide nanoparticles. Today, parameters such as by-product emission, ageing or nanoparticle release are only partially considered for the different positive or negative opinions about PCO.

The aim of the SafePHOTOCAT project was to strengthen the assessment of commercial photocatalytic systems in order to guarantee the safety of the consumers and to actively contribute to the sound development of the photocatalytic market. Accordingly, the performances of four selected commercial photocatalytic air purifiers were analyzed first at the lab-scale and second on experimental platforms under real conditions. At the lab-scale, their efficiencies were determined in a $1.2-\mathrm{m}^{3}$ tight chamber (French standards AFNOR XP-B44-013 and XP-B44-200). In addition to the analysis required by these standards in terms of VOC abatement and mineralization, by-product formation and Clean Air Delivery Rates (CADRs), the ageing of the materials/systems as well as the emission of $\mathrm{TiO}_{2}$ nano/microparticles during their use was also investigated. From the results of these laboratory investigations in a tight chamber, two efficient autonomous devices were selected and studied under real conditions in larger experimental rooms, where the pollution arose from the building material and wooden pieces of furniture. The results obtained in the airtight chamber and under real conditions were correlated.

\section{Materials and methods}

Four commercial air purifiers were bought from the market and used without any modification. For the laboratory study, they were introduced in a clean and purged $1.2-\mathrm{m}^{3}$ tight chamber (Costarramone et al. 2015; Kartheuser et al. 2012). The methodology is described in the XP-B44-013 standard (AFNOR 2009) dedicated to photocatalytic air purifiers including a photocatalytic function, demonstrated by the mineralization of the VOC (i.e. oxidation to carbon dioxide). In this standard, a mixture of four VOCs (acetone, acetaldehyde, heptane, toluene) is introduced in two batch experiments, first at $250 \mathrm{ppbV}$ each (to control by-product formation) and second at $1 \mathrm{ppmV}$ each (to control $\mathrm{CO}_{2}$ production). A first set of inter-laboratory experiments allowed the validation of the airtight chamber and demonstrated the strength and the robustness of the proposed standard by comparing the CADRs for the same photocatalytic device (Kartheuser et al. 2012). CADR represents the "effective" clean airflow rate delivered by the air purifier and is based on the well-mixed single-zone model (Chen et al. 2006). Assuming that the air is well mixed in the chamber and that the contaminant removal mechanisms other than air cleaning (e.g. surface deposition effect and chamber leakage effect) are the same with and without operating air purifier, the reaction can generally be characterized by a first-order rate constant $k_{n}$ when the device is off and $k_{e}$ when the device is on. The mass conservation of contaminant in the "pull-down" test can be written as:

$\frac{d c}{d t}\left(k_{n}+\frac{\mathrm{CADR}}{V}\right) \times c=k_{e} \times c$

where $V$ is the volume of the testing chamber $\left(\mathrm{m}^{3}\right), k_{n}$ the firstorder decay rate constant of contaminant concentration without air cleaner operating (possible adsorption on chamber walls and air cleaner) $\left(\mathrm{h}^{-1}\right), k_{e}$ the first-order decay rate constant of total contaminant concentration with air cleaner operating $\left(\mathrm{h}^{-1}\right), t$ the time (h) and $C$ the contaminant concentration inside the chamber at time $t$ (expressed in $\mathrm{mg} \mathrm{m}^{-3}$ of carbon for total $\mathrm{VOC})$.

Another XP-B44-200 French standard (AFNOR 2011) was alternatively used and confirmed some of the results. In this case, the pollutant mixture is introduced continuously in the chamber by permeation chambers and ozone and nitrogen oxide formation has to be controlled. No detail will be given here.

These laboratory experiments were compared to the results obtained on two experimental platforms EVALIS $\left(16 \mathrm{~m}^{2}, 40 \mathrm{~m}^{3}\right.$, Fig. 1a) and $\operatorname{BEF}\left(12 \mathrm{~m}^{2}, 35 \mathrm{~m}^{3}\right.$, Fig. $\left.1 \mathrm{~b}\right)$. These two platforms contain oriented strand board (OSB) wooden panels and are isolated with glass wool. The main difference is that EVALIS was not thermo-regulated while BEF was. The results on BEF (with additional ventilation 


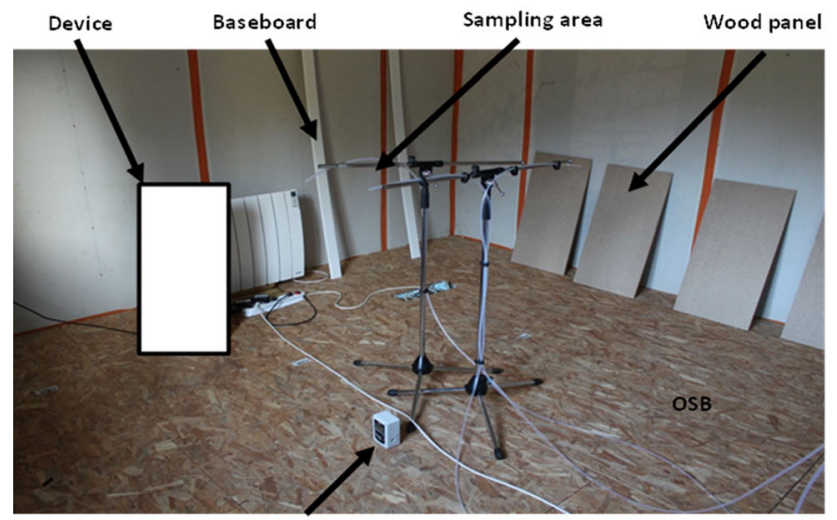

Comfort parameters sensors

a

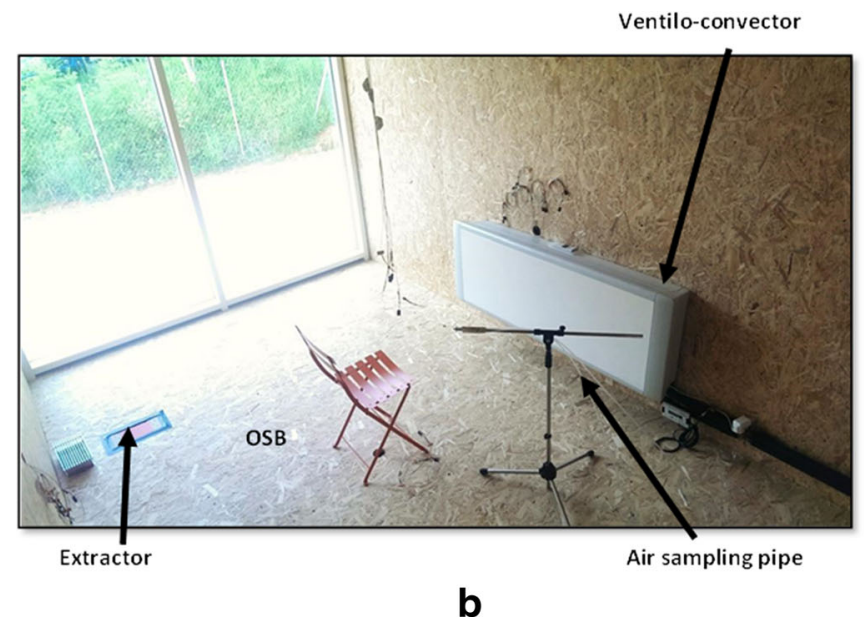

b

Fig. 1 Pictures of a the experimental platform EVALIS and $\mathbf{b}$ the experimental platform BEF

$0.5 \mathrm{~h}^{-1}$ ) will only be detailed here for the two most performing air purifiers selected on the basis of laboratory results.

For laboratory experiments, analysis of $\mathrm{VOC}$ and $\mathrm{CO} /$ $\mathrm{CO}_{2}$ was made with on-line gas chromatographs GC-FID, GC-PID (VOC) and FID-methanizer $\left(\mathrm{CO} / \mathrm{CO}_{2}\right)$ from AIRMOTEC. For both laboratory and platform experiments, aldehyde (mainly formaldehyde) quantification was carried out by HPLC-UV (KNAUER) following a standard method (NF ISO 16000-3) with LpDNPH S10 Cartridges (Supelco) for sampling air. For other VOCs detected in the platforms and possibly formed as intermediate products in laboratory experiments, two different methods were used: in the first method, Air Toxics or Tenax GR stainless steel tubes (Supelco) were used for sampling air (at $0.1 \mathrm{~L} \mathrm{~min}^{-1}$ ) and analyzed using ATD (Turbomatrix 650) coupled with GC (Clarus 680)-MS (Clarus 600S) from PERKIN-ELMER (NF ISO 16000-6). In the second method developed by C2MA (Bourdin and Desauziers 2014; Desauziers et al. 2015), air was sampled instantaneously in vacuum glass bottle $(250 \mathrm{~mL})$ and the VOC (including formaldehyde) pre-concentration was made on solid phase micro-extraction (SPME) fibers impregnated with 0 -2,3,4,5,6-(pentaflurobenzyl)hydroxylamine (PFBHA). Analysis was then achieved by GC-MS (VARIAN 1200Q). For micro- and nanoparticle release, a low-pressure cascade impactor (ELPI, DEKATI) was used to measure on-line the particle size distribution from $10 \mu \mathrm{m}$ to $7 \mathrm{~nm}$ distributed over 13 stages with a time resolution of $10 \mathrm{~s}$. Air was sampled at $10 \mathrm{~L} \mathrm{~min}^{-1}$ flow rate with a corresponding inlet of fresh filtered air (UltraFilter Donaldson DF-P/S 0035 and filter RoHS AFD20F02C) on another port of the chamber. The photocatalytic systems were aged by letting them continuously switched on in the laboratory for a given time (up to 4 months).

\section{Results}

\section{Laboratory experiments for air purifiers: standard XP-B44-013}

As an example, Figs. 2 and 3 show the results obtained according to XP-B44-013 standard with two of the studied air purifiers, E15 and E1, respectively. With device E15, a noticeable adsorption of the four introduced VOCs is observed when the system is off (Fig. 2a), due to the presence of active carbon (Table 1). As soon as the system is switched on, a sharp drop of the pollutant concentration occurs. The total disappearance of the pollutant is observed, either when device E15 is new or after ageing for 125 days (Fig. 2b). With new E15, carbon dioxide evolution is only observed after a 50-min delay, while it occurs immediately after switching on the aged system (Fig. 2c). However, in all experiments with E15, carbon dioxide evolution remains between 25 and $30 \%$ of the theoretical $\mathrm{CO}_{2}$ amount calculated from the drop of pollutant concentration, considering that they are totally mineralized (the pollutant concentrations have to be converted in $\mathrm{m} \mathrm{m}^{-3}$ equivalent carbon).

According to the standard, the possible formation of byproduct has to be checked. In our case, sampling of the air from the chamber on Air Toxics/Tenax and DNPH cartridges for VOC and aldehydes, respectively, was carried out after several minutes for each studied air purifier. The results of by-product formation are summarized in Table 1. With two systems (E8 and E15), no release of any by-product was detected.

Owing to the bad results obtained with the two systems E1 and E10 (emission of volatile by-products by the system alone, insignificant decrease of the concentration of added VOC, Fig. 3), they were discarded from the following analysis. 

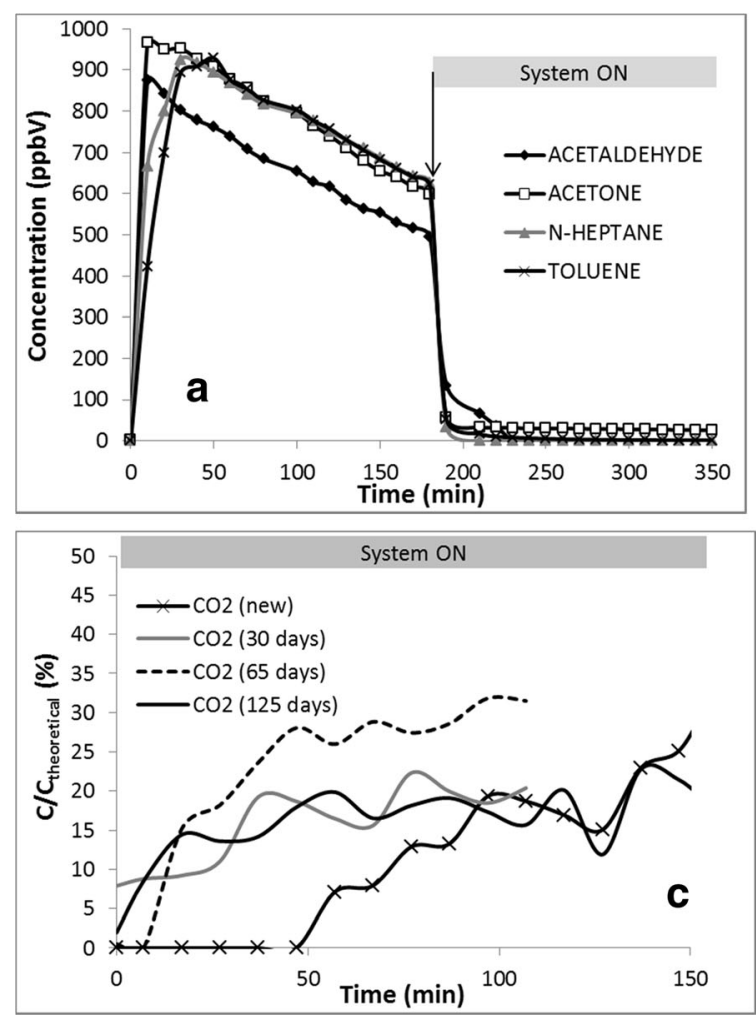

Fig. 2 Examples of results according to XP-B44-013 standard with the photocatalytic air purifier E15. a Evolution of the concentration of individual VOC with time. b Drop of total VOC concentration. $\mathbf{c}$ Evolution of

The CADRs were calculated for individual and total VOC only for the two most efficient systems, E8 and E15 either new or aged (Fig. 4a, b, respectively). As expected, the calculated CADR depends on the initial concentration of pollutants $(250 \mathrm{ppbV}$ or $1 \mathrm{ppmV})$. For system E8, a slight decrease of the CADR is noticed for the aliphatic pollutants (acetone, acetaldehyde, $n$-heptane) while the CADR for toluene removal increases with the system ageing. Changing the lamps after E8 was kept

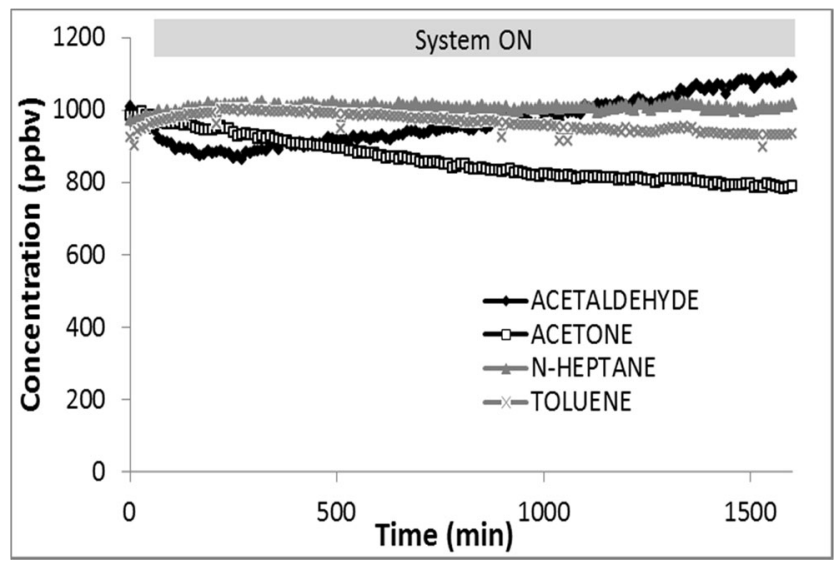

Fig. 3 Evolution of individual VOC concentration with time with the inefficient system E1

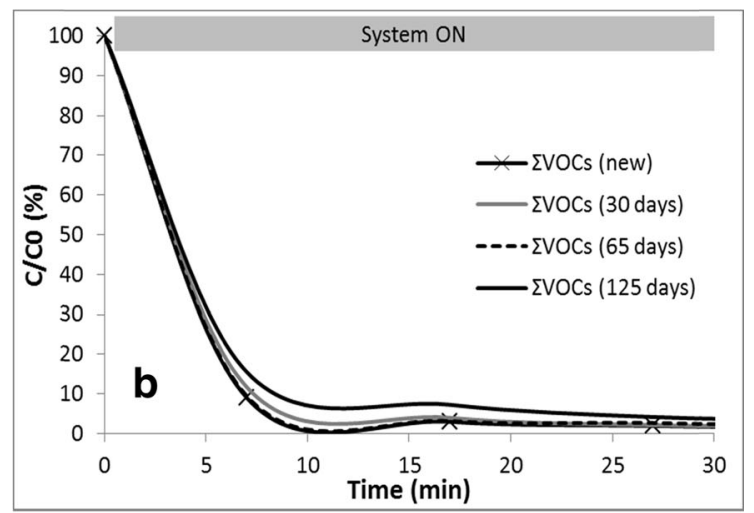

$\mathrm{CO}_{2}$ concentration (concentrations of total $\mathrm{COV}$ were calculated in $\mathrm{mg} \mathrm{m}^{-3}$ equivalent carbon for $\mathbf{b}$ and $\mathbf{c}$ )

continuously switched on for 4 months in the laboratory improves the calculated CADR. This result may be related to the lamp output between 300 and $550 \mathrm{~nm}$ measured after ageing for 4 months $\left(2.2 \mathrm{~mW} \mathrm{~cm}{ }^{-2}\right)$ and with new lamps $\left(5.7 \mathrm{~mW} \mathrm{~cm}^{-2}\right)$. This means that this $61 \%$ output drop in $2880 \mathrm{~h}$ can account for the decreased efficiency of the device. Conversely, the calculated CADR for system E15 decreases only after 4 months ageing. The lamp output between 200 and $800 \mathrm{~nm}$ is more stable than with the previous device $\mathrm{E} 8$ (from 11.5 to $10.8 \mathrm{~mW} \mathrm{~cm}^{-2}$ between the new and aged device). The observed loss in efficiency is this case most probably arises from the poisoning of the photocatalytic media. When comparing the CADR for total VOC for E8 and E15, the values obtained for the latter are between five and nine times those calculated for E8 (Fig. 4c).

The data obtained for E8 and E15 were confirmed when introducing continuously in the chamber a mixture of five pollutants (formaldehyde, acetone, acetaldehyde, $n$-heptane, toluene) by reference to the standard for autonomous air purifiers XP-B44-200. The concentration at the outlet of the chamber was almost zero, and no ozone was detected for both systems. However, with the air purifier E8, NOx emission was noticed, which did not occur when the particle filter was removed. 
Table 1 Description and performances according to XP-B44-013 standard of four selected commercial photocatalytic air purifiers

\begin{tabular}{|c|c|c|c|c|}
\hline System & E1 & E8 & E10 & E15 \\
\hline Lamp & UVC & UVA & Not specified & UVC \\
\hline Additional function & $\begin{array}{l}\text { Filter } \\
\text { Active carbon } \\
\text { Ionizer }\end{array}$ & Filter & $\begin{array}{l}\text { Filter } \\
\text { Ionizer }\end{array}$ & $\begin{array}{l}\text { Filter } \\
\text { Active carbon }\end{array}$ \\
\hline Max flow rate $\left(\mathrm{m}^{3} \mathrm{~h}^{-1}\right)$ & 230 & 250 & 420 & 160 \\
\hline VOC emission with system on alone $\mathrm{a}^{\mathrm{a}}$ & Yes (including formaldehyde) & No & Yes (including formaldehyde) & No \\
\hline By-product emission during the test with VOC & Yes & No & Yes & No \\
\hline $\begin{array}{l}\text { CADR }\left(\mathrm{m}^{3} \mathrm{~h}^{-1}\right)^{\mathrm{b}} \\
\text { New system } \\
\text { Aged system (4 months) }\end{array}$ & ND & $\begin{array}{l}3.7 \\
3.0\end{array}$ & ND & $\begin{array}{l}38.5 \\
23.2\end{array}$ \\
\hline $\mathrm{NO}_{\mathrm{x}}$ emission $^{\mathrm{c}}$ & ND & Yes & Yes & No \\
\hline Micro/nanoparticle emission & No & No & No & No \\
\hline
\end{tabular}

$N D$ not determined

${ }^{a}$ No VOC introduced in the tight chamber

${ }^{\mathrm{b}}$ With concentration of each introduced pollutant at $1 \mathrm{ppmV}$

${ }^{\mathrm{c}}$ Measured according to specifications of XP-B44-200 standard

\section{Laboratory experiments for passive materials}

A surface of $60 \times 60 \mathrm{~cm}^{2}$ of each material was used (Table 2). Paints were layered on glass plates according to the supplier instructions. Two irradiation sources were used with a ceiling light (size $60 \times 60 \mathrm{~cm}^{2}$ ) equipped with four fluorescent tubes Philips $18 \mathrm{~W} / 940$ (visible light: 2.1 to $3.3 \mathrm{~mW} \mathrm{~cm}^{-2}$ between

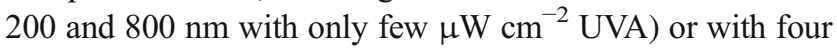
dark light fluorescent tubes Philips $18 \mathrm{~W} 370 \mathrm{~nm}$ (UVA light 0.5 to $1.4 \mathrm{~mW} \mathrm{~cm}^{-2} \mathrm{UVA}$ ). The variation of the measured lamp output depends on the sensor position on the material surface relative to the position of the fluorescent tubes (maximum in the center, minima in the corners).

Under these conditions, the photocatalytic tiles $\mathrm{C} 5$ and the paint $\mathrm{P} 2$ did not show any quantifiable VOC reduction whatever the irradiation source (visible or UVA). Only the paint P3 showed a significant VOC mineralization under UVA, but much weaker under visible light (Table 2, Fig. 5). The ageing of this paint under visible irradiation under indoor air conditions led to a decrease of its performances, but always quantifiable after 4.5 months (Fig. $5 \mathrm{~d}$ ).

\section{Pilot experiments for air purifiers}

The two most efficient systems E8 and E15 selected from the previous standard experiments were then placed in the larger BEF experimental platform and analyzed under real conditions. The temperature $\left(25^{\circ} \mathrm{C}\right)$ and relative humidity $(60$ $80 \% \mathrm{HR}$ ) were recorded all along the experiments. No additional pollution other than that arising from the wooden floor and pieces of furniture was introduced. The main characterized VOCs, together with their initial concentration, are displayed on Fig. 6. Besides the light VOCs (formaldehyde, acetaldehyde and acetone), toluene, limonene, hexanal, pentanal, octanal, nonanal, $\alpha$ - and $\beta$-pinene, 3 -carene and 1 pentanol were detected, with $\alpha$-pinene, hexanal and acetone in most significant concentrations. Figure 6 clearly shows a neat decrease of the heaviest VOC after 5 days working for E8
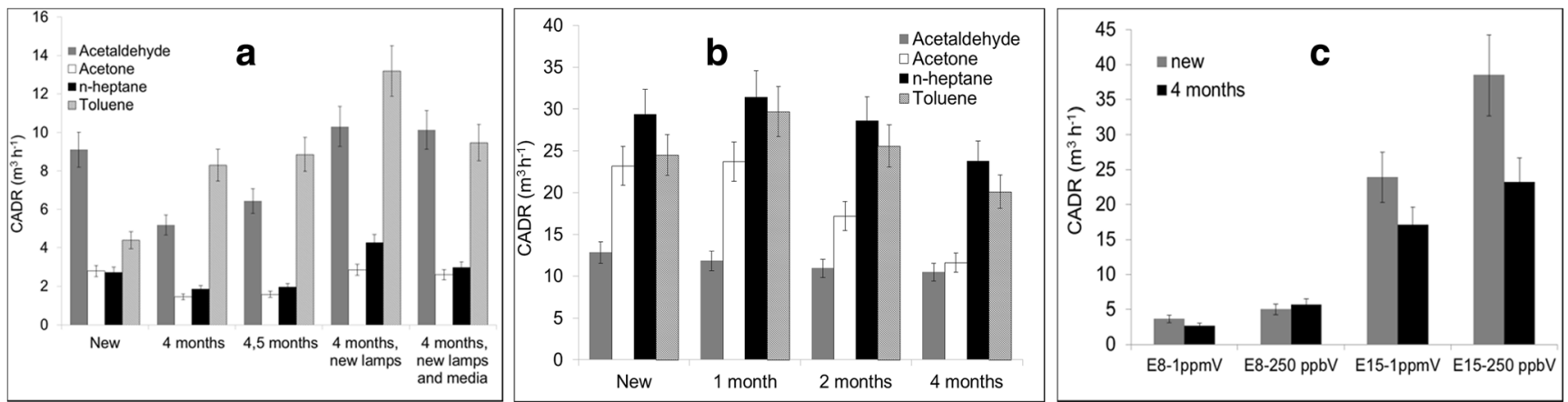

Fig. 4 Influence of system ageing (system continuously switched on in the laboratory during the time indicated on the $x$ axis) on the calculated CADR on individual VOC (standard XP-B44-013, each pollutant

introduced at $1 \mathrm{ppmV}$ ) with air purifier a E8, b E15 and c comparison of calculated CADR on total VOC for E8 and E15 starting with $250 \mathrm{ppbV}$ or $1 \mathrm{ppmV}$ pollutant concentration with new or aged (4 months) systems 
Table 2 Description and performances of three photocatalytic commercial materials (according to XP-B44013 standard)

\begin{tabular}{llll}
\hline Materials & C5 & P2 & P3 \\
\hline Material kind & Tile & Paint & Paint \\
Irradiation & Visible/UVA & Visible/UVA & Visible/UVA \\
VOC emission with materials alone & No & No & No \\
$\mathrm{CO}_{2}$ emission with materials alone & No & No & Yes \\
VOC degradation & No & No & Yes \\
Micro/nanoparticle release & No & No & No \\
\hline
\end{tabular}

and after 3.5 days working for E15. However, during the same time, acetone concentration was not affected by E8, while formaldehyde and acetaldehyde concentrations increased from 12 to $26 \mu \mathrm{g} \mathrm{m}^{-3}$ and from 15 to $28 \mu \mathrm{g} \mathrm{m}^{-3}$, respectively. The same trend was observed with E15: formaldehyde concentration increased from 15 to $20 \mu \mathrm{g} \mathrm{m}^{-3}$ maximum while acetaldehyde and acetone concentrations only decreased by 10 and $22 \%$, respectively.

The results obtained in the $1.2-\mathrm{m}^{3}$ airtight chamber according to the XP-B44-013 standard (with formaldehyde added to the initial pollutant mixture) and in the 40- $\mathrm{m}^{3}$ EVALIS and $35-\mathrm{m}^{3}$ BEF platforms under real conditions are compared (Fig. 7). Formaldehyde, acetaldehyde and acetone totally disappeared after 4 or $2 \mathrm{~h}$ in
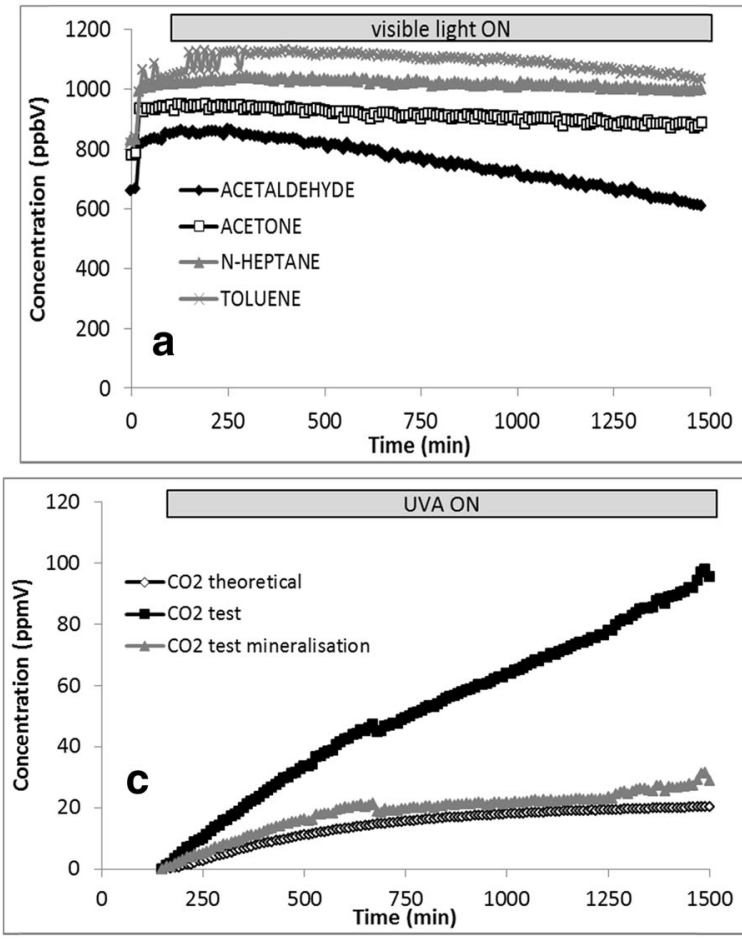

Fig. 5 Experiments in these airtight chambers under visible and UVA light with paint P3. a Evolution of VOC concentrations under visible light. b Evolution of VOC concentrations under UVA. c Evolution of $\mathrm{CO}_{2}$ concentration under UVA (white circles theoretical $\mathrm{CO}_{2}$ from mineralization deduced from the decrease of VOC concentration, black squares total experimental $\mathrm{CO}_{2}$, grey triangles experimental $\mathrm{CO}_{2}$ due to VOC mineralization (difference between total $\mathrm{CO}_{2}$ during the test with the airtight chamber, while their degradation was either slower or not observed in the two experimental platforms.

Even if not required by the standards, the emission of micro/nanoparticles by the air purifiers E1, E8, E10 and E15 while working was analyzed both in the airtight chamber (Fig. 8a, b) and in the experimental platforms BEF and EVALIS (Fig. 8c, d). In all the cases, the number of micro/nanoparticles was higher without the system than inside the considered chamber or platform containing the switched on system. This result implies that none of the analyzed air purifier emitted $\mathrm{TiO} 2$ particles or that the filters inside the air purifier efficiently retained any emitted particle.
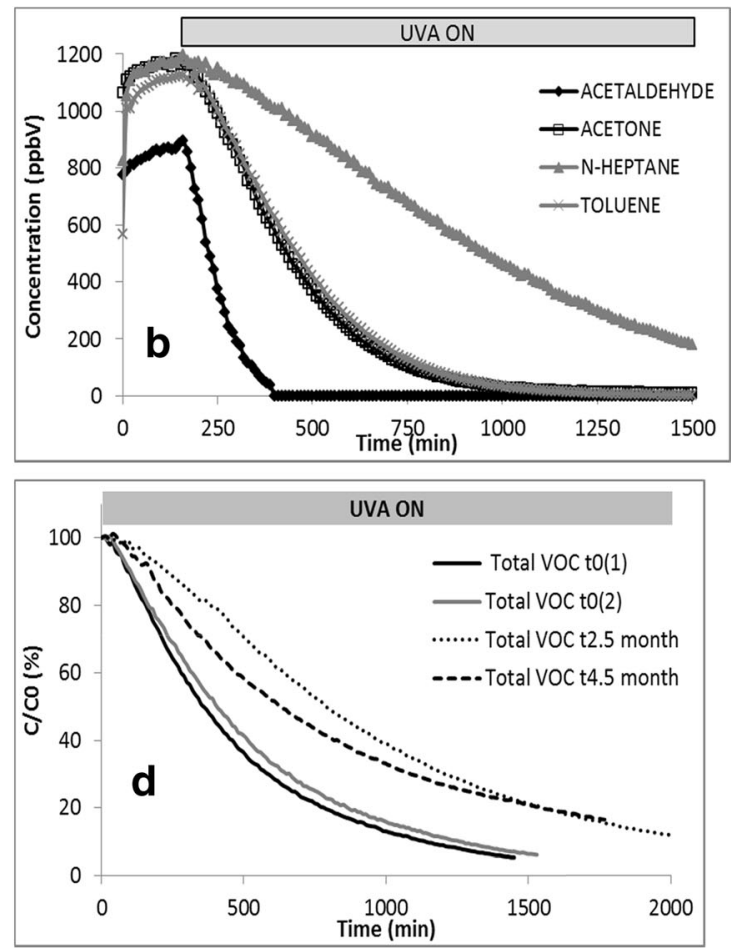

added VOC and during the test without VOC). d Drop of total VOC concentration with paint ageing. Evolution of VOC concentration with the two most efficient photocatalytic air purifiers: a E8 switched ON for 2 and 5 days and $\mathbf{b}$ E15 (4 months ageing) switched on for 3.5 days in the experimental platform BEF. The numbers on the bars are the initial VOC concentration $\left(\mu \mathrm{g} \mathrm{m}^{-3}\right)$ 


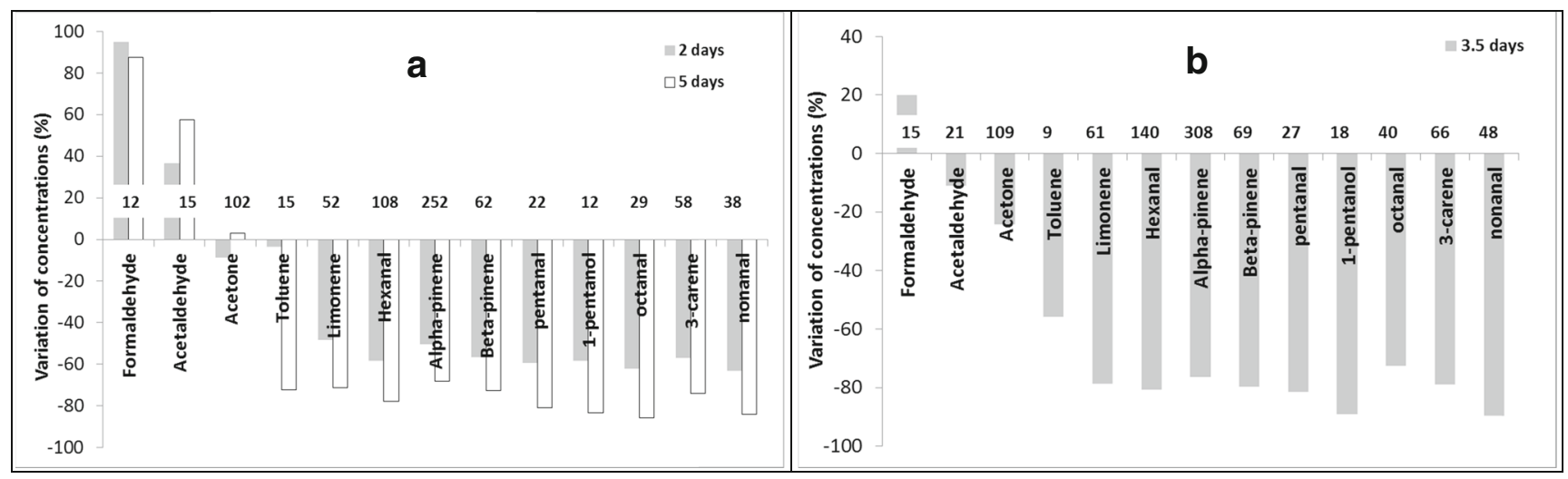

Fig. 6 Evolution of VOC concentration with the two most efficient photocatalytic air-purifiers a E8 switched ON for 2 and 5 days; b E15 (4 months aging) switched $\mathrm{ON}$ for 3.5 days in the experimental platform BEF. The numbers on the bars are the initial VOC concentration $(\mu \mathrm{g}$ m-3)

\section{Discussion}

At the European level, inside the working group 2 (WG2, air purification) of the CEN TC386 devoted since several years to normalization in photocatalysis, one standard is nowadays under inquiry: it is based on AFNOR XP-B44-013 and dedicated to the measurement of efficiency of photocatalytic devices used for the elimination of VOC and odor in indoor air in active mode (prEN 16846-1:2015). The main difference with the AFNOR standard is the introduction of a mixture of five VOCs, adding formaldehyde to the four previous ones, with two batch experiments at 50 and $1000 \mathrm{ppbV}$ each pollutant, respectively. Another European technical specification CEN/ TS WI 00386023 proposes a new method for determination of the degradation of nitric oxide (NO) in air by photocatalytic materials.

As shown in this study, normalized tests are useful for discarding inefficient and unsafe commercial air purifiers (such as E1 and E10 emitting some VOC when switched on). The standard experiments also allowed selecting two efficient devices, E8 and E15. E15 did not release any significant by-product when working, while E8 was shown to produce $\mathrm{NO}_{\mathrm{x}}$. This $\mathrm{NO}_{\mathrm{x}}$ emission was due to the instability of the particle filter under irradiation and did not occur when it was removed. (This information was sent to the system manufacturer.) It is especially relevant that with these two systems under our conditions in the airtight chamber, only very low formaldehyde emission $(<20 \mathrm{ppbV})$ was detected as the sole intermediate by-product. It may be recalled here that we previously demonstrated the fast oxidation (by another efficient photocatalytic system) of formaldehyde added in the four pollutant mixtures at several concentrations in the airtight chamber (Kartheuser et al. 2012).

Even if CADR on total VOC may sometimes be calculated with some errors, these values are useful for ranking photocatalytic air purifiers. Here, for instance, it is obvious that system E8 has globally a lower CADR than E15, either new or aged. Replacement of the lamps of E8 improves the CADR, while replacement of the photocatalytic media has a lower effect (Fig. 3a). With this system, for toluene as individual VOC, ageing appears to improve the CADR, while it rather decreases for individual acetaldehyde, acetone and $n$-heptane.

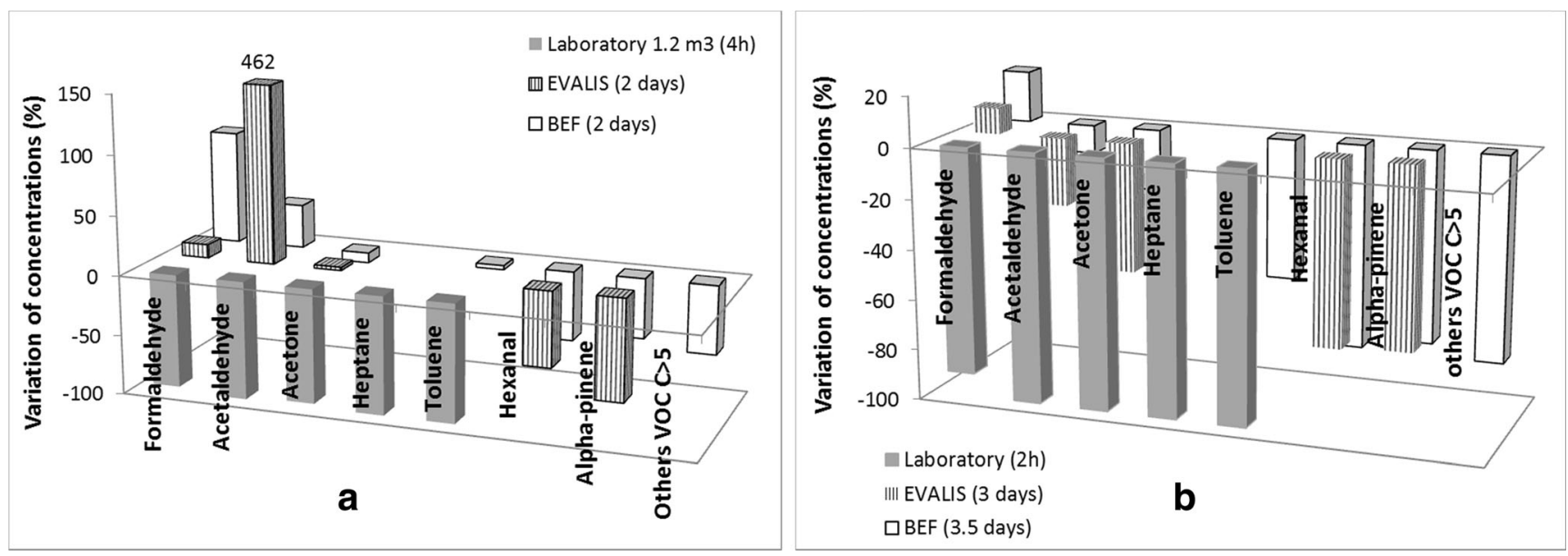

Fig. 7 Evolution of VOC concentration with the two most efficient photocatalytic air purifier a E8 (number 462 was added on the bar because it was out of scale), $\mathbf{b}$ E15 in the airtight chamber or in experimental platforms EVALIS and BEF 

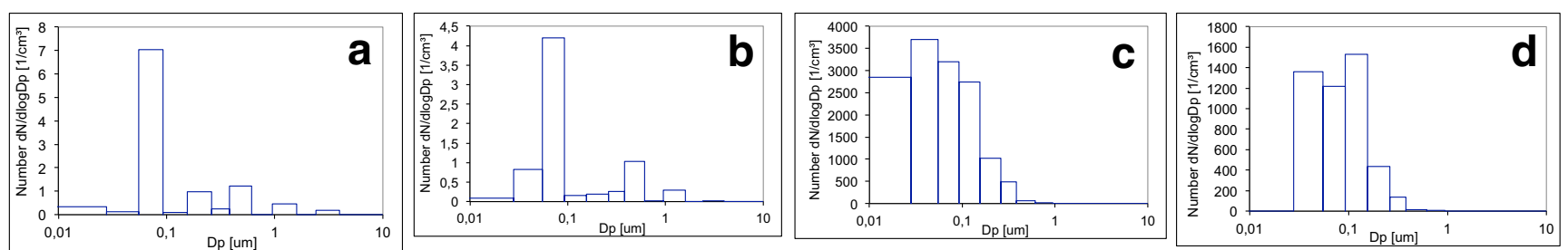

Fig. 8 Measurements of micro/nanoparticles by ELPI. a control blank inside the flushed airtight chamber, $\mathbf{b}$ inside the airtight chamber with E15 ON for $4 \mathrm{~h}, \mathbf{c}$ control outside the BEF platform, $\mathbf{d}$ inside the BEF platform with E15 ON after 30 days of continuous run, measured the same days as $\mathbf{c}$

For total VOC, the calculated CADR decreases slightly with ageing after noting a maximum value after 1 month. This result probably means that the photocatalytic media or the lamp had to stabilize for this system. On the other hand, with E15, the calculated CADR is rather stable after 2 months continuous switched on and decreases more quickly only after 4 months (Fig. 3b, c).

With E15, even if no by-product was detected, mineralization was only $25-30 \%$ at the end of the experiment. This result, as well as the delay for $\mathrm{CO}_{2}$ evolution when the system was new (Fig. 2c), is probably related to the presence of active carbon, strong adsorbent of the VOC (total mineralization would only occur when the VOC are desorbed from active carbon) and probably of $\mathrm{CO}_{2}$. At this stage, no definitive conclusion can be drawn from these data.

A rather good correlation was found between airtight chamber and experimental platform results, even if the VOCs were totally different between the two sets of experiments. In the platforms containing mainly OSB (wooden) panels, acetone, $\alpha$-pinene and heavy aldehydes were mainly found in significant concentrations. Under these conditions $\left(0.5 \mathrm{~h}^{-1}\right.$ additional ventilation in the BEF platform, $25^{\circ} \mathrm{C}$, $60-80 \% \mathrm{RH})$, the concentrations of the higher weight VOC efficiently decreased when the air purifiers E8 or E15 were switched on for several days. However, the formation of light intermediate VOCs (formaldehyde, acetaldehyde, acetone) was noticed in both cases, probably arising from the continuous but incomplete mineralization of the heavier ones. With both E8 and E15, the concentrations of formaldehyde, acetaldehyde and acetone were either stable or slightly increased but remained lower than the authorized ones $\left(100 \mu \mathrm{g} \mathrm{m} \mathrm{m}^{-3}\right.$ for formaldehyde according to World Health Organization (WHO) short-term guideline recommendation). The same type of data was obtained by (Gunschera et al. 2016) with main formation of formaldehyde $(50 \mathrm{ppbV})$ and acetone $(80 \mathrm{ppbV})$ as intermediate products in 24 and $48 \mathrm{~m}^{3}$ emission chambers using inlet VOCs. It must also be stressed that some parameters such as relative humidity, temperature and external ventilation of the platform will probably influence these results (Hay et al. 2015; Zhong et al. 2010). The production of formaldehyde and acetaldehyde has thus to be carefully controlled each time this type of devices is used in order to insure that their concentration does not exceed threshold values.
Among the three passive materials tested in the laboratory airtight chamber (a tile $\mathrm{C} 5$ and two paints $\mathrm{P} 2$ and $\mathrm{P} 3$ ), only the paint $\mathrm{P} 3$ showed measurable photocatalytic properties for VOC mineralization, with a much higher efficiency under UV irradiation than under visible light (Fig. 5b, a). A decrease of its efficacy was however recorded with ageing of this paint (continuous irradiation in the laboratory under visible light for 4.5 months, Fig. 5 d).

It is also important to emphasize that no micro/nanoparticle emission by any of the studied air purifier or material could be observed, but rather that the number of the micro/ nanoparticles naturally present in the atmosphere rather decreased when the air purifiers were working.

\section{Conclusion}

This work emphasizes the importance of analyzing the efficiency of photocatalytic systems claiming an air-purification function. In the commercial advertisements, some results of experimental studies are sometimes given, but very often, the conditions of these tests are not detailed or are not suitable. The definition of robust standards is thus the first step to discard inefficient and/or unsafe product and to give some indications/advices to manufacturers for improving their products. A good correlation of these standard experiments with actual conditions of use were demonstrated, even if lower weight VOCs are continuously produced in low and acceptable concentration by mineralization of heavier ones in a real room.

Certification of these commercial products would be the last step to ensure appropriate efficacy and safety to the consumers using such air purifiers and to ensure a sound development of the market, since well-designed photocatalytic systems proved their efficacy to decrease the concentrations of several VOC in indoor air by their mineralization to carbon dioxide.

Acknowledgments The authors acknowledge ADEME for funding SafePHOTOCAT project and Ministère de l'Economie et de l'Emploi, Direction Générale Compétitivité Industrie et Services (DGCIS), for funding the NORMACAT project labelled by the Axelera cluster. 


\section{References}

AFNOR, December 2009 XP B44-13 - Méthode d'essais et d'analyse pour la mesure d'efficacité de systèmes photocatalytiques pour l'élimination des composés organiques volatiles/odeurs dans l'air intérieur en recirculation: test en enceinte confinée.

AFNOR, May 2011 XP B44-200 - Épurateurs d'air autonomes pour applications tertiaires et résidentielles - Méthode d'essais Performances intrinsèques.

Bernstein JA, Alexis N, et al. (2008) Reviews and feature article: the health effects of nonindustrial indoor air pollution. J Allergy Clin Immunol 121(3):585-591

Bourdin D, Desauziers V (2014) Development of SPME on-fiber derivatization for the sampling of formaldehyde and other carbonyl compounds in indoor air. Anal and BioanalChem 406(1):317-328

Chen W, Gao Z, Zhang JS, Kosar D, Walker CE, Novosel D (2006) Reduced energy use through reduced indoor contamination in residential buildings, National Center for Energy Management and Buildings Technologies, Final Report NCEMBT 061106

Costarramone N, Kartheuser B, Pécheyran C, Pigot T, Lacombe S (2015) Efficiency and harmfulness of air-purifying photocatalytic commercial devices: from standardized chamber tests to nanoparticles release. Catalysis today, 8th European meeting on solar chemistry and photocatalysis. Environmental Applications 252:35-40

Desauziers V, Bourdin D, Mocho P, Plaisance H (2015) Innovative tools and modeling methodology for impact prediction and assessment of the contribution of materials on indoor air quality. Heritage Science 3:1

Destaillats H, Sleiman M, Sullivan DP, et al. (2012) Key parameters influencing the performance of photocatalytic oxidation (PCO) air purification under realistic indoor conditions. Appl Catal B Environ 128:159-170

Gunschera J, Markewitz D, Bansen B, et al. (2016) Portable photocatalytic air cleaners: efficiencies and by-product generation. Environ Sci Pollut Res 23:7482-7493
Hay SO, Obee T, Luo Z, et al. (2015) The viability of photocatalysis for air purification. Molecules 20:1319-1356

Jones AP (1999) Review article: indoor air quality and health. Atmos Environ 33:4535-4564

Kartheuser B, Costarramone N, Pigot T, Lacombe S (2012) NORMACAT project: normalized closed chamber tests for evaluation of photocatalytic VOC treatment in indoor air and formaldehyde determination. Environ Sci Pollut Res 19:3763-3771

Kolarik J, Wargocki P (2010) Can a photocatalytic air purifier be used to improve the perceived air quality indoors? Indoor Air 20:255-262

Leung DYC (2015) Outdoor-indoor air pollution in urban environment: challenges and opportunity. Front Environ Sci. doi:10.3389/fenvs.2014.00069

Luengas A, Barona A, Hort C, et al. (2015) A review of indoor air treatment technologies. Rev Environ Sci Biotechnol 14:499-522

Mo J, Zhang Y, Xu Q, J. JL, R. Z (2009) Photocatalytic purification of volatile organic compounds in indoor air: a literature review. Atm Environ 43:229-2246

Paz Y (2010) Review: application of $\mathrm{TiO}_{2}$ photocatalysis for air treatment: patents' overview. Appl Catal B Environ 99:448-460

Squinazi F (2002) La pollution de l'air à l'intérieur des bâtiments (allergènes exclus). Rev Fr Allergol Immunol Clin 42:248-255

Tompkins D. Lawnicki B., Zeltner W. (2005) Anderson M. Evaluation of Photocatalysis for Gas-Phase Air Cleaning Part 1: Process, Technical, and Sizing Considerations. ASHRAE Trans. 2, 111, paper no. 4791, 60-84.

Zeltner W.A., Tomkins D.T. (2005) Shedding light on photocatalysis. ASHRAE Trans. 2, 111, paper no. DE-05-5-1, 523-534.

Zhang Y, Mo J, Li Y, et al. (2011) Can commonly-used fan-driven air cleaning technologies improve indoor air quality? A literature review. Atmos Environ 45:4329-4343

Zhong L, Haghighat F, Blondeau P, Kozinski J (2010) Modeling and physical interpretation of photocatalytic oxidation efficiency in indoor air applications. Build Environ 45:2689-2697 